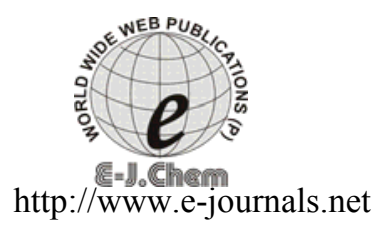

ISSN: 0973-4945; CODEN ECJHAO
E-Journal of Chemistry
2011, 8(S1), S502-S508

\title{
Characterization and Thermal Analysis of Mercury Complexes Containing Intermolecular $\mathbf{N} \rightarrow \mathbf{H g}$ Interactions
}

\author{
HAJAR SAHEBALZAMANI $^{\S *}$, FARSHID SALIMI ${ }^{\S}$ and SHAHRIARE GHAMMAMY \\ ${ }^{\S}$ Departments of Chemistry, Faculty of Science \\ Ardabil Branch, Islamic Azad University, Ardabil, Iran \\ ${ }^{\#}$ Department of Chemistry, Faculty of Science \\ Islamic Azad University, Malard Branch, Tehran, Iran \\ sahebalzamanih@yahoo.com
}

Received 18 February 2011; Accepted 28 April 2011

\begin{abstract}
The new mercury (II) compounds with $\left(\mathrm{L}^{1}\right),\left(\mathrm{L}^{2}\right)$ of the general formula $\left[\operatorname{Hg}(\mathrm{L})_{2}\right]$, have been synthesized and characterized by elemental analysis, electronic and IR, Raman spectra and thermogravimetry and differential thermogravimetry techniques. The changes observed between the spectra of the ligands and of the complexes allowed us to stablish the coordination mode of the metal in complexes and the mechanism of $\mathrm{C}-\mathrm{H}$ activation is discussed in detail. Thermogravimetry (TG), differential thermal analysis (DTA) and other analytical methods have been applied to the investigation of the thermal behavior and structure of the compounds $\left[\mathrm{Hg}(\mathrm{L})_{2}\right]$. Thermal decomposition of these compounds is multi-stage processes.
\end{abstract}

Keywords: Organomercury, Hydrazine ligands, Synthesis, Thermal properties

\section{Introduction}

Mercury containing ligands e.g., mercuric and mercurous are known to form stable complexes with class $\mathrm{b}$ metal ions, such as gold(I $)^{1,2}$ and $\mathrm{Se}(\mathrm{II})^{3}$ because mercury is considered to be a soft Lewis base $e^{4,5}$. The coordination chemistry of transition metals with ligands from the hydrazine family has been of interest due to different bonding modes shown by these ligands with both electron rich and electron poor metals ${ }^{6-8}$. 
The $\mathrm{C}-\mathrm{H}$ activation obviously depends on both the electron density on the metal and that on the $\mathrm{C}-\mathrm{H}$ bond that is to be activated, and may be promoted by steric hindrance ${ }^{9,10}$. The $\mathrm{C}-\mathrm{H}$ bond is much stronger than the $\mathrm{M}-\mathrm{C}$ bond and the thermodynamic barrier for homolytic cleavage of a $\mathrm{C}-\mathrm{H}$ bond is high ${ }^{11}$. This has opened up its broad synthetic potential and $\mathrm{C}-\mathrm{H}$ functionalization has become an important topic in organometallic chemistry ${ }^{12,13}$.

We now report the synthesis the complexes [4-[(2,4-dinitro-phenyl)-hydrazonomethyl)]phenol] $\mathrm{Hg}(\mathrm{II})$ (1), [N-(2,4-dinitro-phenyl)- $N$-(3-nitro-benzylidene)-hydrazine $] \mathrm{Hg}$ (II) (2) and study the role of nitro groups towards metal assisted $\mathrm{C}-\mathrm{H}$ activation of 2,4-dinitrophenyl hydrazine derivatives ${ }^{10}$.

\section{Experimental}

All reagents were supplied by Merck and were used without further purification. Melting points were determined using Electrothermal 9200. The Raman spectra were recorded with an Omnac spectrophotometer. The FT-IR spectra were recorded in the range $400-4000 \mathrm{~cm}^{-1}$ by $\mathrm{KBr}$ pellet using a Brucker Tensor $27 \mathrm{M} 420$ FT-IR spectrophotometer. The UV-Vis spectra in $\mathrm{CH}_{3} \mathrm{CN}$ were recorded with a WPA bio Wave S2 100 spectrophotometer.

\section{Preparation of Ligands}

The ligands $\mathrm{L}^{1}-\mathrm{L}^{2}$ were dissolved by 2 , 4-dinitrophenyl hydrazine $(0.39 \mathrm{~g}, 2 \mathrm{mmol})$ in $10 \mathrm{~mL}$ absolute acetonitrile under tempture $60{ }^{\circ} \mathrm{C}$ and addition of this solution derivatives aldehyde ( $2 \mathrm{mmol}$ dissolved in $5 \mathrm{~mL}$ absolute ethanol) was added. The reaction mixture was refluxed for $2 \mathrm{~h}$. After cooling, the precipitate solid was collected, filtered off and finally washed with $5-10 \mathrm{~mL}$ cold absolute ethanol and re-crystallized from ethanol (Scheme 1).

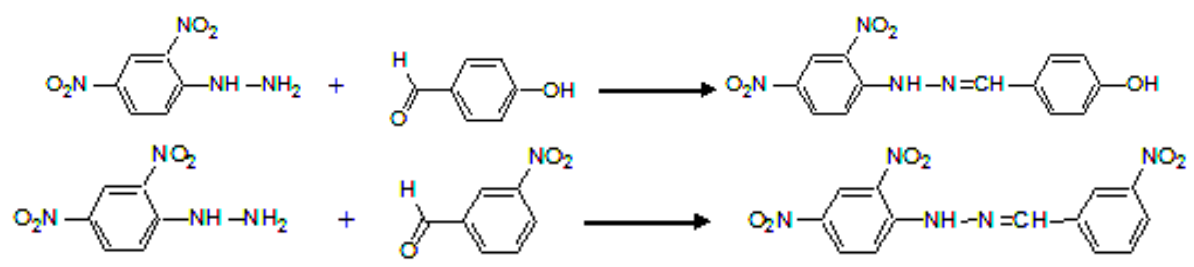

Scheme 1. Schematic representation of ligands formation of compounds

Synthesis of complex [4-[(2,4-Dinitro-phenyl)-hydrazonomethyl)]-phenol] $\mathrm{Hg}(\Pi)$ $\left[\mathrm{Hg}\left(L^{1}\right)_{2}\right]$ (1)

Mercury chloride $(1 \mathrm{mmol})$ was dissolved in absolute acetonitrile $(5 \mathrm{~mL})$. To this, $(3 \mathrm{mmol})$ $N$-(2,4-dinitro-phenyl)- $N$-(3-phenyl-allylidene)-hydrazine in DMF $(10 \mathrm{~mL})$ was added. The mixture was stirred magnetically at room temperature. The precipitated solid was filtered, washed with $\mathrm{H}_{2} \mathrm{O}$ and hexane and then was allowed to stand for $3 \mathrm{~d}$ at room temperature whereupon the red solid precipitate was deposited. IR (KBr): $3277(\mathrm{~m}) \mathrm{cm}^{-1} v(\mathrm{~N}-\mathrm{H}, \mathrm{str}$.), $1619(\mathrm{~s}) \mathrm{cm}^{-1} v(\mathrm{C}=\mathrm{N}$, str. $), 1586$ (s) $\mathrm{cm}^{-1} v(\mathrm{C}-\mathrm{C}, \mathrm{str}),. 1328(\mathrm{~s}) \mathrm{cm}^{-1} v\left(\mathrm{NO}_{2} \mathrm{sy}, \mathrm{str}.\right), 1216(\mathrm{~m})$ $\mathrm{cm}^{-1} v\left(\mathrm{~N}-\mathrm{H}\right.$ in-plane). Raman: $1610 \mathrm{~cm}^{-1} v(\mathrm{C}=\mathrm{N}$, str. $), 1580 \mathrm{~cm}^{-1} v(\mathrm{C}-\mathrm{C}, \mathrm{str}),. 1390 \mathrm{~cm}^{-1}$ $v\left(\mathrm{NO}_{2}\right.$ sy, str.), $1280 \mathrm{~cm}^{-1} v\left(\mathrm{~N}-\mathrm{H}\right.$ in-plane). UV-Vis $\left(\mathrm{CH}_{3} \mathrm{CN}\right): \lambda_{\max }(\log \varepsilon): 243(4.41)$, 281(4.20), 389(4.7) nm.

$$
\begin{aligned}
& \mathrm{C}_{6} \mathrm{H}_{6} \mathrm{~N}_{4}+\mathrm{C}_{7} \mathrm{H}_{6} \mathrm{O}_{2} \stackrel{\mathrm{CH}_{3} \mathrm{CN}}{\longrightarrow} \mathrm{C}_{6} \mathrm{HNHN}=\mathrm{CH}-\mathrm{C}_{6} \mathrm{H}_{4} \mathrm{OH}+\mathrm{H}_{2} \mathrm{O} \\
& 2 \mathrm{C}_{6} \mathrm{H}_{6} \mathrm{NHN}=\mathrm{CH}-\mathrm{C}_{6} \mathrm{H}_{4} \mathrm{OH}+\mathrm{HgCl}_{2} \longrightarrow \mathrm{C}_{26} \mathrm{H}_{18} \mathrm{~N}_{8} \mathrm{O}_{10} \mathrm{Hg}+2 \mathrm{HCl}
\end{aligned}
$$


Synthesis of complex [N-(2,4-Dinitro-phenyl) N-(3-nitro-benzylidene)-hydrazine] $\mathrm{Hg}(\mathrm{II})\left[\mathrm{Hg}\left(\mathrm{L}^{2}\right)_{2}\right](2)$

Complex (2) was synthesized in a similar manner to that used for complex (1), reacting a mixture of $\left(\mathrm{L}^{2}\right)(3 \mathrm{mmol})$ and $\mathrm{HgCl}_{2}(1 \mathrm{mmol})$ in DMF $(10 \mathrm{~mL})$. IR $(\mathrm{KBr}): 3281(\mathrm{~m}) \mathrm{cm}^{-1}$ $v(\mathrm{~N}-\mathrm{H}, \mathrm{str}),. 1615(\mathrm{~s}) \mathrm{cm}^{-1} v(\mathrm{C}=\mathrm{N}$, str. $), 1587(\mathrm{~s}) \mathrm{cm}^{-1} v(\mathrm{C}-\mathrm{C}, \mathrm{str}), 1331(\mathrm{~s}) \mathrm{cm}^{-1} v\left(\mathrm{NO}_{2} \mathrm{sy}\right.$, str.), $1221(\mathrm{~m}) \mathrm{cm}^{-1} v(\mathrm{~N}-\mathrm{H}$ in-plane $)$. Raman: $1620 \mathrm{~cm}^{-1} v(\mathrm{C}=\mathrm{N}, \mathrm{str}),. 1570 \mathrm{~cm}^{-1} v(\mathrm{C}-\mathrm{C}, \mathrm{str}$.$) ,$ $1380 \mathrm{~cm}^{-1} v\left(\mathrm{NO}_{2}\right.$ sy, str. $), 1230 \mathrm{~cm}^{-1} v(\mathrm{~N}-\mathrm{H}$ in-plane $)$. UV-Vis $\left(\mathrm{CH}_{3} \mathrm{CN}\right): \lambda \max (\log \varepsilon): 247$ (4.28), 277 (4.09), 380(4.46) nm.

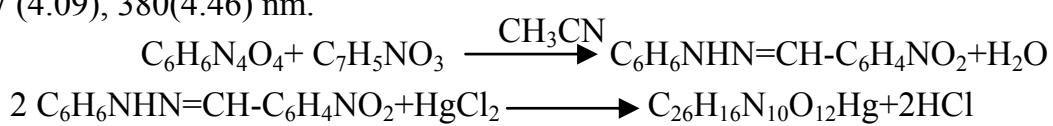

\section{Results and Discussion}

Elemental analysis data and physical properties are summarized in Table 1 . The complexes were prepared in good yield by stirring stoichiometric amounts of $\mathrm{HgCl}_{2}$ and $\mathrm{L}^{1}, \mathrm{~L}^{2}$. The complexes are stable in air and light and are soluble in organic solvents such as $\mathrm{CHCl}_{3}$ and DMSO, less soluble in methanol and insoluble in and water and $n$-hexane.

Table 1. The physical and analytical data of the ligands and complexes

\begin{tabular}{|c|c|c|c|c|c|c|c|c|}
\hline \multirow{2}{*}{$\begin{array}{c}\text { Comp. } \\
\text { no. }\end{array}$} & \multirow{2}{*}{$\begin{array}{l}\text { Molecular } \\
\text { formula }\end{array}$} & \multirow{2}{*}{$\begin{array}{l}\text { M. } \\
\text { Wt. }\end{array}$} & \multirow{2}{*}{ Color } & \multirow{2}{*}{$\stackrel{\text { M.P }}{{ }^{\circ} \mathrm{C}}$} & \multirow{2}{*}{ Solubility } & \multicolumn{3}{|c|}{$\begin{array}{l}\text { Elemental Analysis } \\
\text { Found (Calc.) }\end{array}$} \\
\hline & & & & & & $\% \mathrm{C}$ & $\% \mathrm{H}$ & $\% \mathrm{~N}$ \\
\hline $\mathrm{L}^{1}$ & $\mathrm{C}_{13} \mathrm{H}_{10} \mathrm{~N}_{4} \mathrm{O}_{5}$ & 231 & Dark-red & 283 & DMF & $\begin{array}{c}51.65 \\
(51.81)\end{array}$ & & $\begin{array}{c}18.54 \\
(18.48)\end{array}$ \\
\hline $\mathrm{L}^{2}$ & $\mathrm{C}_{13} \mathrm{H}_{9} \mathrm{~N}_{5} \mathrm{O}_{6}$ & 207 & Orange & 297 & DMF & $\begin{array}{c}47.14 \\
(47.25)\end{array}$ & $\begin{array}{c}2.74 \\
(2.68)\end{array}$ & $\begin{array}{l}21.14 \\
(21.20)\end{array}$ \\
\hline 1 & $\mathrm{C}_{26} \mathrm{H}_{18} \mathrm{~N}_{8} \mathrm{O}_{10} \mathrm{Hg}$ & 663 & Red & 272 & $\begin{array}{l}\mathrm{DMSO} \\
\mathrm{CHCl}_{3}\end{array}$ & $\begin{array}{c}38.87 \\
(38.95)\end{array}$ & $\begin{array}{c}2.24 \\
(2.19)\end{array}$ & $\begin{array}{l}13.95 \\
(14.01)\end{array}$ \\
\hline 2 & $\mathrm{C}_{26} \mathrm{H}_{16} \mathrm{~N}_{10} \mathrm{O}_{12} \mathrm{Hg}$ & 686 & Yellow & 285 & $\begin{array}{l}\text { DMSO, } \\
\mathrm{CHCl}_{3}\end{array}$ & $\begin{array}{r}36.25 \\
(36.34) \\
\end{array}$ & $\begin{array}{l}1.85 \\
(1.86) \\
\end{array}$ & $\begin{array}{c}16.26 \\
(16.31) \\
\end{array}$ \\
\hline
\end{tabular}

IR, Raman spectra

The modes of the coordinated ligands in the complexes have been investigated by means of IR absorption spectra. The presence of electron withdrawing substituents such as a $\mathrm{NO}_{2}$ group on the aryl ring was regarded to inhibit cyclometallation by rendering the aryl ring as an electrophile, which in turn would have made it unavailable for the attack of an electron deficient metal center ${ }^{14}$.

There are some significant changes between the metal(II) complexes and their free ligands for chelation as expected. An exhaustive comparison of the IR spectra of the ligands and complexes gave information about the mode of bonding of the ligands in metal complexes. The IR spectrum of $\left[\mathrm{HgL}_{2}\right]$ complexes, the ligands acts as a neutral bidentate through the azomethine nitrogen atom and carbon atom, which is meta to both the $\mathrm{NO}_{2}$ groups.

The presence of a sharp band at $1586,1587 \mathrm{~cm}^{-1}$ in IR spectrum and sharp band at 1580 , $1570 \mathrm{~cm}^{-1}$ in Raman spectrum, owing to the $v(\mathrm{C}-\mathrm{C})$ (ring) vibrations in the complexes (1), (2) respectively.

In the IR spectra of the complexes a sharp medium band at $1619,1615 \mathrm{~cm}^{-1}$ in IR spectrum and sharp medium band at $1610,1620 \mathrm{~cm}^{-1}$ in Raman spectrum owing to the $v(C=N)$ 
(azomethine) vibrations is shifted to lower frequencies in complexes (1), (2) respectively which indicates the use of the azomethine group as one of the coordinating sites of the ligand. The coordination of nitrogen to the metal atom would be expected to reduce the electron density on the azomethine link and thus cause a shift in the $\mathrm{C}=\mathrm{N}$ band.

In the FT-Raman spectra the $\mathrm{N}-\mathrm{H}$ in-plane bending vibrations assigned in the region $1280,1230 \mathrm{~cm}^{-1}$ and for the $\mathrm{N}-\mathrm{H}$ out-of-plane bending falls in the FT-Raman values of $1000-1070 \mathrm{~cm}^{-1}$ for the complexes (1), (2) respectively (Figure 1). In the FT-IR spectra the band due to $\mathrm{NH}$ stretching in the free ligands occurs in the $3276-3285 \mathrm{~cm}^{-1}$ region and remains unaffected after complexation. This precludes the possibility of coordination through the hydrazine nitrogen atom.

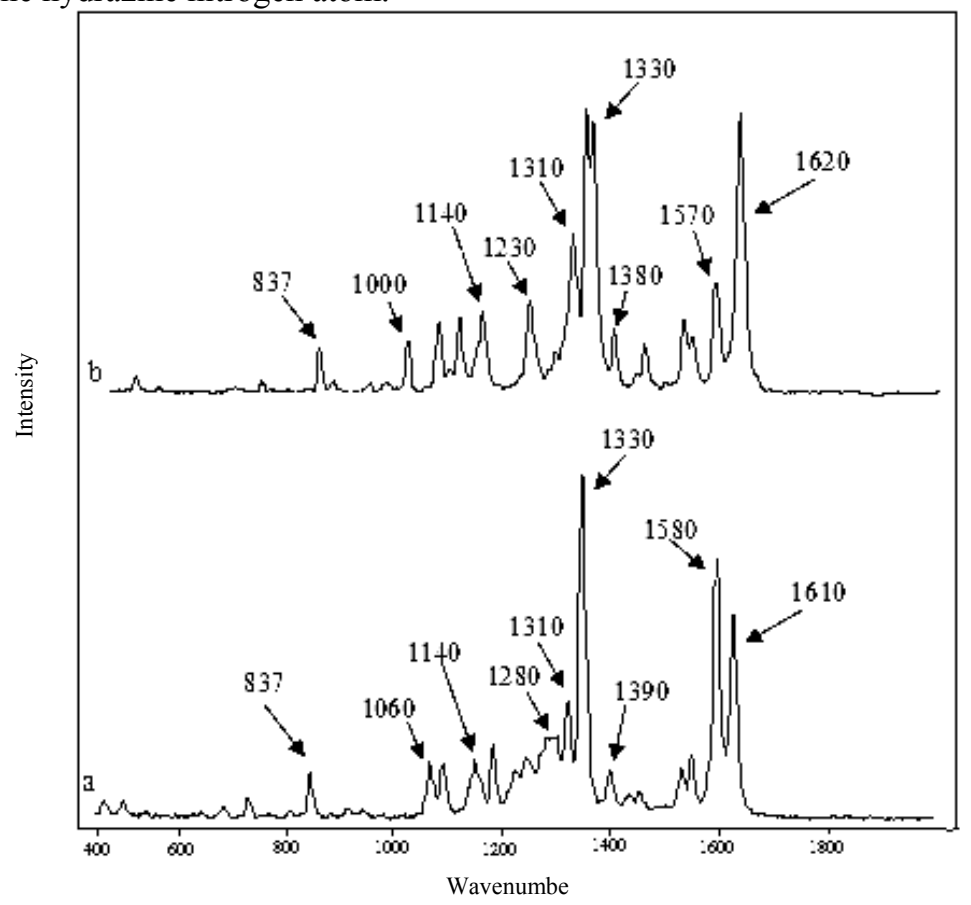

Figure 1. Raman spectra of (a) $\left[\mathrm{Hg}\left(\mathrm{L}^{1}\right)_{2}\right]$, (b) $\left[\mathrm{Hg}\left(\mathrm{L}^{2}\right)_{2}\right]$

The deformation vibrations of $\mathrm{NO}_{2}$ group contribute to several normal modes in the low frequency region. The medium band at $837 \mathrm{~cm}^{-1}$ in FT-Raman spectrum is assignable to $\mathrm{NO}_{2}$ scissoring mode. Aromatic nitro compounds have medium absorption due to the symmetric stretching vibrations of the $\mathrm{NO}_{2}$ group at $1390-1310,1380-1310 \mathrm{~cm}^{-1}$ regions in FT-Raman spectrum and in FT-IR spectrum absorption due to the symmetric stetching vibrations of the $\mathrm{NO}_{2}$ group at $1328,1331 \mathrm{~cm}^{-1}$ in the complexes (1), (2) respectively. The small shift to higher frequency of the band due to $v(\mathrm{~N}-\mathrm{N})$ can be taken as additional evidence of the participation of the azomethine group in bonding.

\section{Electronic spectra}

The formation of the metal(II) complexes was also confirmed by UV-Vis spectra. The UV-Vis solution spectra of the ligands and complexes were also recorded (Figures 2 and 3). When compared complexes with the free ligands values have shifts frequency. All the complexes exhibited three to four bands in the region $243-389 \mathrm{~nm}$. The two absorption bands 
appearing in the range 243,247 and $277,281 \mathrm{~nm}$ may be assigned to a $\pi \rightarrow \pi^{*}$ transition of the aromatic ring and $\mathrm{a} \rightarrow \pi^{*}$ transition of the $-\mathrm{C}=\mathrm{N}$ group, respectively. In addition, the low energy absorption peaks in the wavelength range $380-391 \mathrm{~nm}$ are associated with a charge transfer transition. The spectra of the complexes do not show any $d-d$ transitions ${ }^{15,16}$.

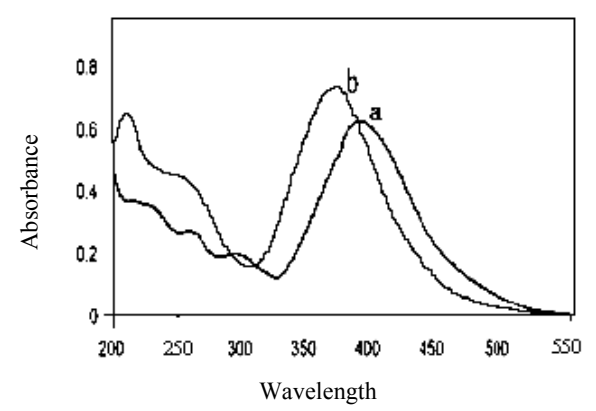

Figure 2. UV-Vis spectra of free ligands (a) $\mathrm{L}^{1}$, (b) $\mathrm{L}^{2}$

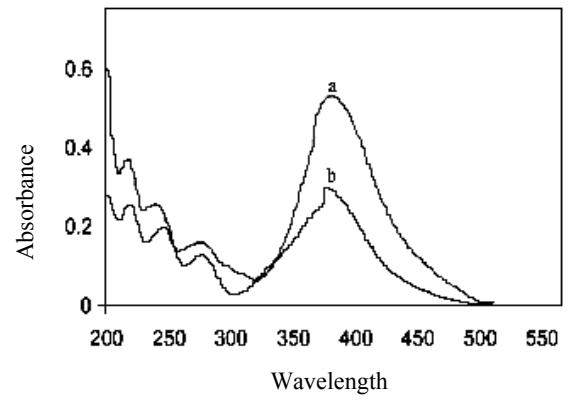

Figure 3. UV-Vis spectra of (a) $[\mathrm{Hg}$ $\left.\left(\mathrm{L}^{1}\right)_{2}\right]$, (b) $\left[\mathrm{Hg}\left(\mathrm{L}^{2}\right)_{2}\right]$

\section{Thermal analysis}

The thermal properties of metal(II) complexes were investigated by thermograms (TG, DTG and DTA) and are shown in (Figure 4, 5) and the corresponding thermal analysis data is presented in Table 2 .

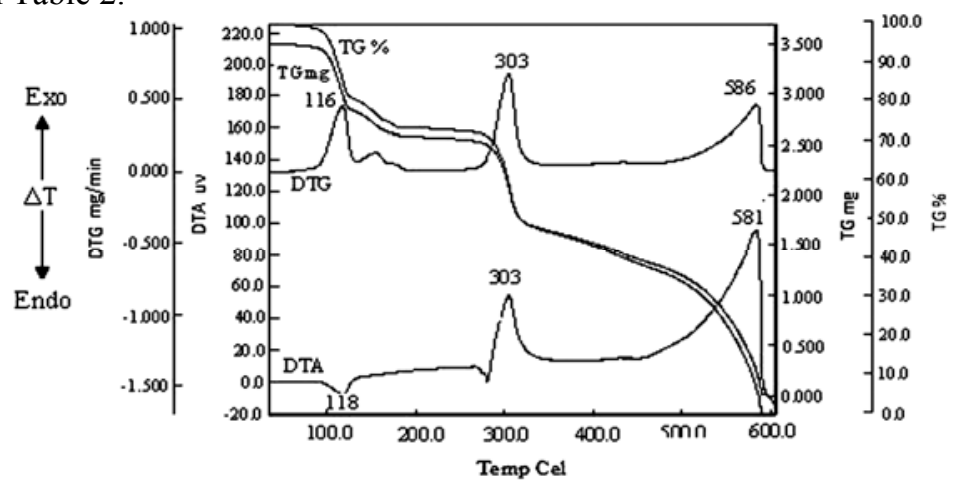

Figure 4. The TG-DTA curves of complex (1)

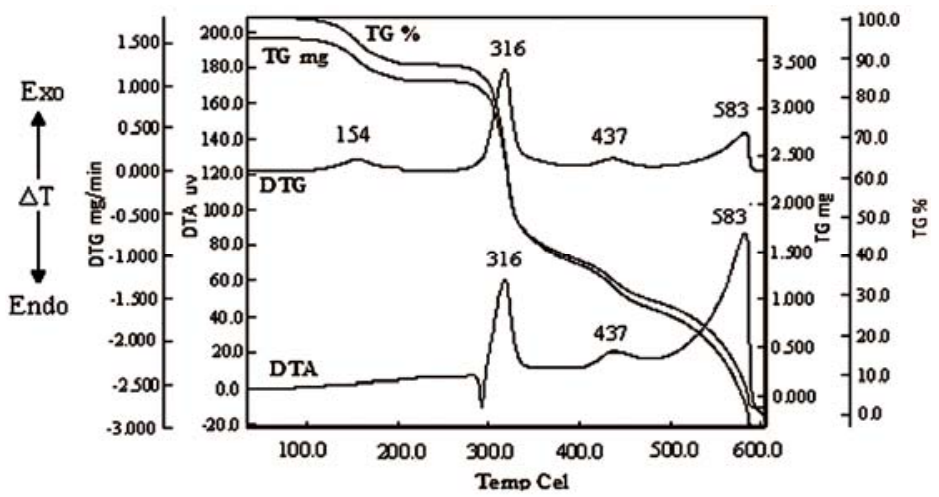

Figure 5. The TG-DTA curves of complex (2) 
Table 2. Phenomenological data for the thermal decomposition of the obtained complexes

\begin{tabular}{|c|c|c|c|c|c|c|}
\hline \multirow{2}{*}{ Complexes } & \multirow{2}{*}{$\begin{array}{c}\text { TG results } \\
T_{\text {rang },}{ }^{\circ} \mathrm{C} \\
\end{array}$} & \multirow[t]{2}{*}{ Stage } & \multirow{2}{*}{$\begin{array}{c}\text { DTA results } \\
T_{\text {peaks }},{ }^{\circ} \mathrm{C} \\
\end{array}$} & \multirow{2}{*}{$\begin{array}{c}\text { DTG results } \\
T_{\text {peaks }},{ }^{\circ} \mathrm{C} \\
\end{array}$} & \multicolumn{2}{|c|}{ Mass loss, $\%$} \\
\hline & & & & & Calculated & Found \\
\hline \multirow[t]{3}{*}{1} & $85-135$ & 1 & 118 (endo) & 116 (exo) & 18.33 & 17.87 \\
\hline & $266-325$ & 2 & 303 (exo) & 303 (exo) & 23.91 & 24.39 \\
\hline & $488-588$ & 3 & 581 (exo) & 580 (ехо) & 30.41 & 31.15 \\
\hline \multirow[t]{4}{*}{2} & $110-203$ & 1 & - & 154 (exo) & 11.47 & 12.15 \\
\hline & $279-360$ & 2 & 316 (exo) & 316 (exo) & 47.13 & 47.84 \\
\hline & $415-469$ & 3 & 437 (exo) & 437 (exo) & 9.42 & 9.97 \\
\hline & $528-590$ & 4 & $583(\mathrm{exo})$ & 583 (exo) & 23.77 & 24.32 \\
\hline
\end{tabular}

In the case of complex (1) (Figure 4), the decomposition occurs in the $85-588{ }^{\circ} \mathrm{C}$ range. There is no mass loss up to $85^{\circ} \mathrm{C}$. The first stage of decomposition starts at $85^{\circ} \mathrm{C}$ and ends at $135{ }^{\circ} \mathrm{C}$ with a corresponding weight loss $18 \%$, Which is accompanied by endothermic effect in the DTA curve in the range 118 which is accompanied by weight loss confirming. The second stage of decomposition is observed at $266-325^{\circ} \mathrm{C}(23 \% \mathrm{wt}$ loss). Meanwhile the DTA curve exhibits exothermic effect in the range $303{ }^{\circ} \mathrm{C}$ which is accompanied by weight loss confirming. The three stage of decomposition starts at $488{ }^{\circ} \mathrm{C}$ and ends at $588{ }^{\circ} \mathrm{C}(30 \% \mathrm{wt}$ loss. The DTA curve exhibits exothermic effect in the range $581{ }^{\circ} \mathrm{C}$ which is accompanied by weight loss confirming.

In the case of complex (2) (Figure 5), there is no mass loss up to $110{ }^{\circ} \mathrm{C}$. The first stage of decomposition starts at $110{ }^{\circ} \mathrm{C}$ and ends at $203^{\circ} \mathrm{C}$ with a corresponding weight loss $11 \%$. The second stages of decomposition were observed at $279-360{ }^{\circ} \mathrm{C}(47 \% \mathrm{wt}$ loss $)$. Meanwhile the DTA curve exhibits exothermic effect in the range $316^{\circ} \mathrm{C}$ which are accompanied by weight loss confirming. The three stage of decomposition was observed at $415-469{ }^{\circ} \mathrm{C}(9 \%$ wt loss). The DTA curve exhibits exothermic effect in the range $437{ }^{\circ} \mathrm{C}$ which is accompanied by weight loss confirming. The four stage of decomposition was observed at, $528-590{ }^{\circ} \mathrm{C}$ (23\% wt loss) for (2) complex. The DTA curve exhibits exothermic effect for complex (2) in the range $583{ }^{\circ} \mathrm{C}$ which is accompanied by weight loss confirming. TGA in air (Figures 4, 5) shows that decomposition with weight loss occurs above $110{ }^{\circ} \mathrm{C}$ for complexes (2), which is higher than for complexes (1) at $85^{\circ} \mathrm{C}$. Clearly, complex (2) has excellent thermal stability.

\section{Conclusion}

In this study we have reported the synthesis of new hydrazine derivatives and their $\mathrm{Hg}(\mathrm{II})$ complexes. The structural characterizations of synthesized compounds were made by using the elemental analysis, FT-IR and FT-Raman spectroscopy, UV spectral techniques. Thermal properties, TG-DTA of these complexes were studied too. From the spectroscopic characterization, it is concluded that ligands acts as a neutral bidentate through the azomethine nitrogen atom and carbon atom, which is meta to both the $\mathrm{NO}_{2}$ groups.

\section{References}

1. Eikens W, Kienitz C, Jones P G and Thone C A, J Chem Soc Dalton Trans., 1994, 83 .

2. Ahmad S, Isab A A, Al-Arfaj A R and Arnold A P, Polyhedron, 2002, 21, 2099.

3. Isab Anvarhusein A, Wazeer Mohammed I M, Fettouhi Mohammed, Ahmad Saeed and Ashraf Waqar, Polyhedron, 2006, 25(13), 2629-2636.

4. Arnold A P, Tan K S and Rabenstein D L, Inorg Chem., 1986, 25, 2433-2437. 
5. Devillanova F A andVerani G, Transit Met Chem., 1977, 2, 9.

6. Wang M, Volkert E W, Singh P R, Katti K K, Lusiak P, Katti K V and Barnes C L, Inorg Chem., 1994, 33, 1184.

7. $\quad$ Katti K V, Reddy V S and Singh P R, Chem Soc Rev., 1995, 24, 97-107.

8. Katti K V, Singh P R and Barnes C L, Inorg Chem., 1992, 31, 4588.

9. Abbenhuis H C L, Pfeffer M, Sutter J P, de Cian A, Fischer J, Ji H L and Nelson J H, Organometallics, 1993, 12, 4464.

10. Alsters P L, Engel P F, Hogerheide M P, Copijn M, Spek A L and Koten G van Organometallics, 1993, 12, 1831.

11. Halpern J, Acc Chem Res., 1982, 15, 238-244.

12. Ryabov A D, Sukharev V S, Alexandrova L, Lagadec R L and Pfeffer M, Inorg Chem 2001, 40, 6529-6532.

13. Matsubara T, Koga N, Musaev D G and Morokuma K, J Am Chem Soc., 1998, 120, 12692.

14. Cope A C and Friedrich E C, J Am Chem Soc., 1968, 90, 909.

15. Salib A R, Stefun S L, El-Wafa S M A and El-Shafiy H F, Synth React Inorg Met Org Chem., 2001, 31(5), 895.

16. Greaney M A, Coyle C L, Harmer M A, Jordan A and Stifel E I, Inorg Chem..,1989, 28, 912-920. 


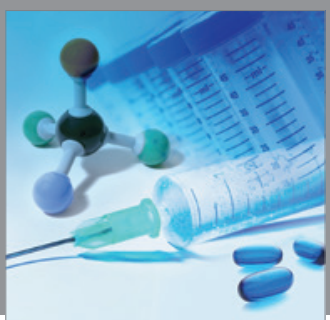

International Journal of

Medicinal Chemistry

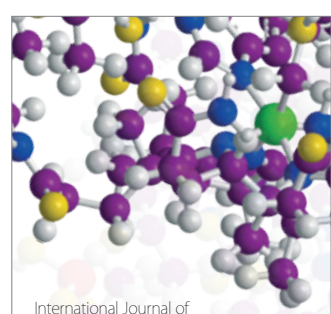

Carbohydrate Chemistry

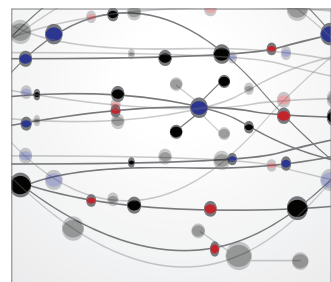

The Scientific World Journal
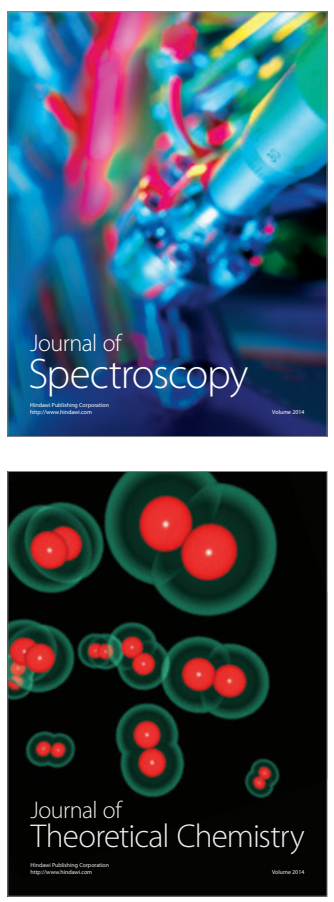
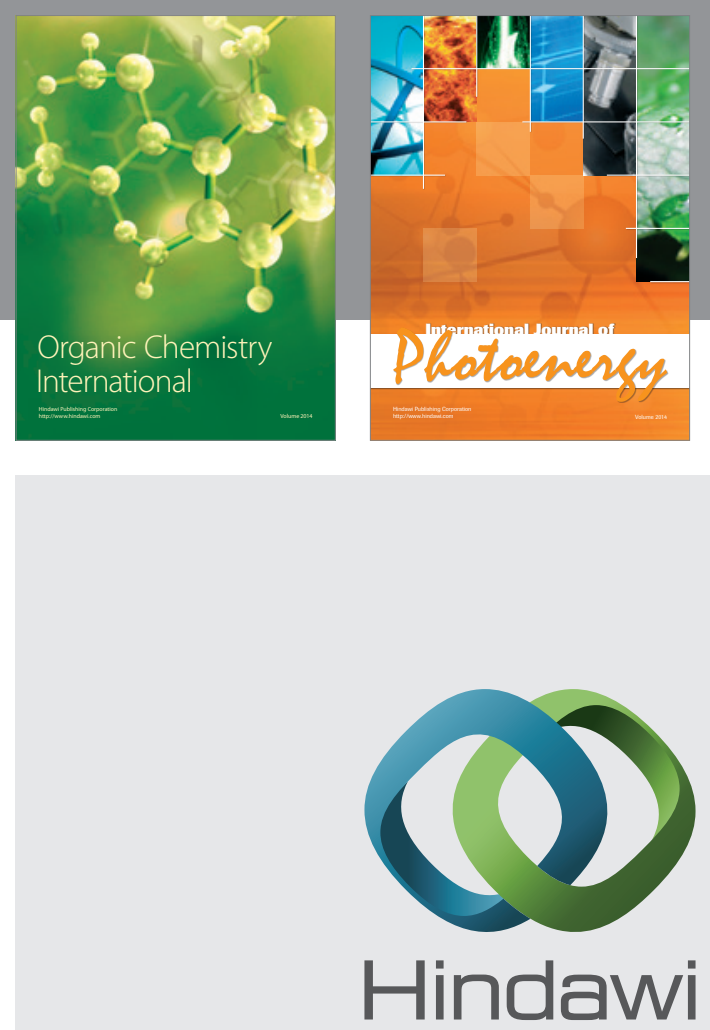

Submit your manuscripts at

http://www.hindawi.com
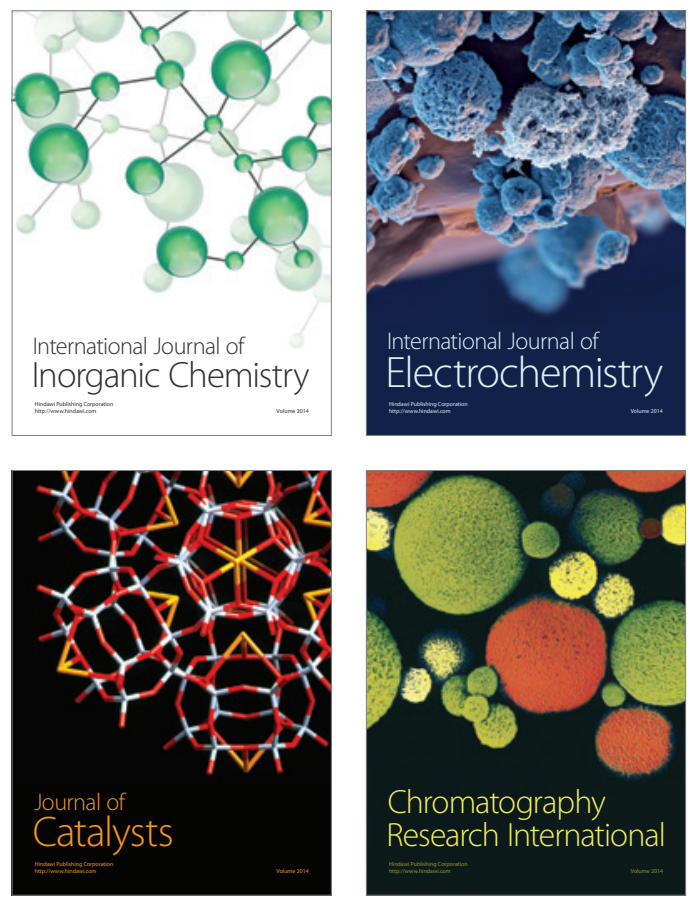
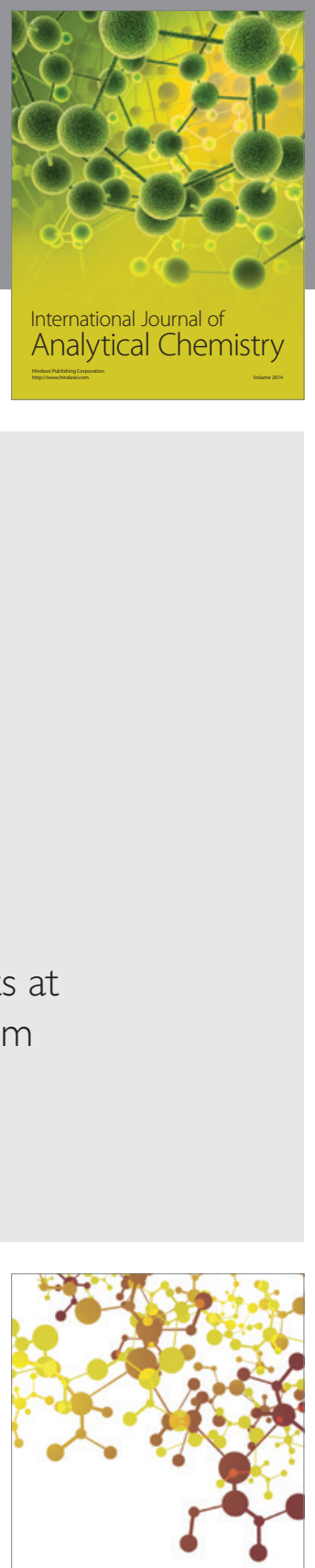

Journal of

Applied Chemistry
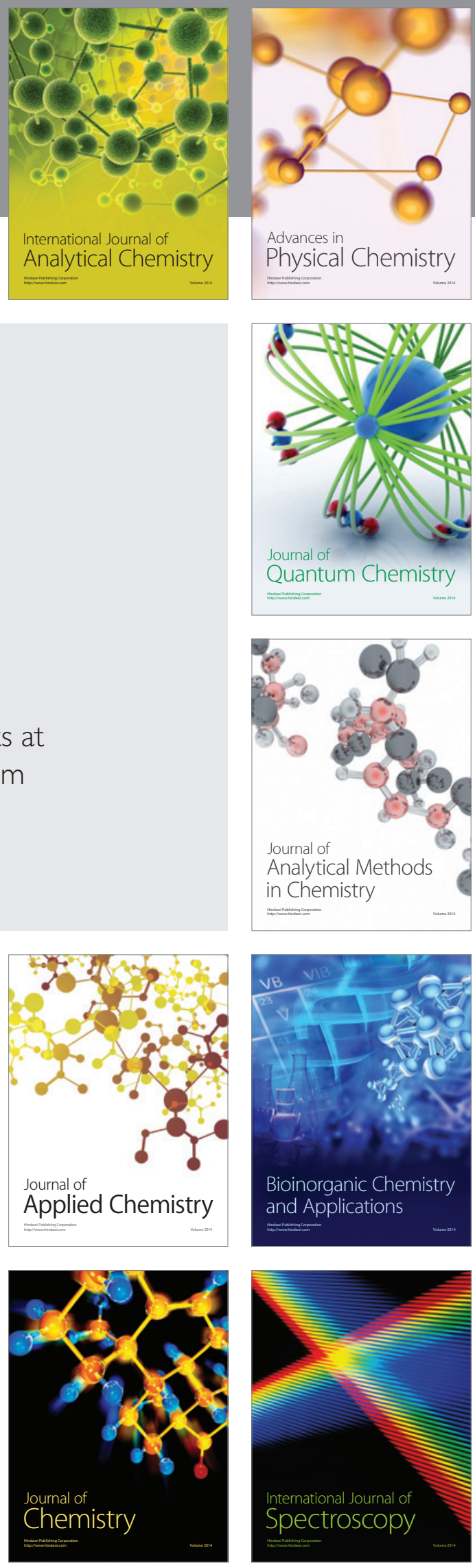